\title{
(6) OPEN ACCESS \\ Influence of progressive addition lenses on reading posture in myopic children
}

\author{
Jinhua Bao, ${ }^{1,2}$ Yuwen Wang, ${ }^{1,2}$ Zuopao Zhuo, ${ }^{1,2}$ Xianling Yang, ${ }^{1,2}$ Renjing Tan, ${ }^{1,2}$ \\ Björn Drobe, ${ }^{2,3}$ Hao Chen ${ }^{1,2}$
}

${ }^{1}$ School of Ophthalmology and Optometry, Wenzhou Medical University (WMU), Wenzhou, Zhejiang, China

${ }^{2}$ WEIRC, WMU-Essilor International Research Centre, Wenzhou, Zhejiang, China ${ }^{3}$ R\&D Asia, Essilor International, Wenzhou, Zhejiang, China

\section{Correspondence to} Professor Hao Chen, School of Ophthalmology and Optometry, Wenzhou Medical University, 270 Xueyuan Road, Wenzhou, Zhejiang 325027, China; chenhao@mail.eye.ac.cn

Received 16 June 2015 Accepted 28 October 2015 Published Online First 25 November 2015

\section{CrossMark}

\author{
To cite: Bao J, Wang $Y$, \\ Zhuo Z, et al. Br J \\ Ophthalmol \\ 2016:100:1114-1117.
}

\section{ABSTRACT}

Aims To determine the influence of single-vision lenses (SVLS) and progressive addition lenses (PALs) on the near vision posture of myopic children based on their near phoria.

Methods Sixty-two myopic children were assigned to wear SVLs followed by PALs. Eighteen children were esophoric (greater than +1 ), 18 were orthophoric $(-1$ to 1$)$ and 26 were exophoric (less than -1$)$ at near. Reading distance, head tilt and ocular gaze angles were measured using an electromagnetic system after adaptation to each lens type.

Results The lens type did not influence reading distance or head tilt angle ( $p>0.05$ for both), but ocular gaze angle decreased significantly with the PALs $(F=9.25, p=0.004)$. With the PALs, exophoric children exhibited significantly increased head tilt angle $(p=0.003)$ and reduced ocular gaze angle $(p=0.004)$ compared with esophoric children. Near non-exophoric children exhibited similar eye and head postures when wearing SVLS and PALs, whereas exophoric children exhibited reduced ocular gaze angle $(t=-3.18, p=0.04)$ with PALs compared with SVLs. Using PALs for reading, the mean addition power employed by esophoric children was significantly greater than exophoric children ( $p=0.04$ ).

Conclusions The lens type and the near phoria state affected near vision posture. During reading, myopic esophoric children used a lower portion of their PALs compared with exophoric children, resulting in greater addition power. These results may partially explain why myopic children with near esophoria exhibited superior treatment effects in myopia control trials using PALs.

\section{INTRODUCTION}

For many years, progressive addition lenses (PALs) have been used for myopic children to slow the progression of myopia. ${ }^{1-7}$ The rationale for the use of PALs is that children with accommodative lag during near work experience hyperopic retinal defocus, which may lead to axial elongation and the development of myopia. ${ }^{8-11}$ Near additions might slow the progression of myopia by reducing the amount of hyperopic defocus by decreasing the accommodative demand and thus the accommodative lag during near vision work. ${ }^{12-14}$ Although various trials have failed to demonstrate that PALs have clinically meaningful treatment effects, ${ }^{1} 24715$ several subgroup analyses have suggested that near additions represent a clinically viable spectacle treatment for slowing the progression of myopia in children with near esophoria ${ }^{3-5}$ and/or children with near esophoria associated with high-accommodative lag. ${ }^{4}{ }^{5}$ However, PALs do not help to reduce the progression of myopia in subjects with near exophoria. ${ }^{3-5}$ The reasons underlying these differences remain unclear.

Accommodation and convergence are the key factors in the oculomotor near response mechanism. In near vision, additions decrease accommodative convergence due to the accommodationconvergence linkage, resulting in a more divergent phoria position. Jiang $e a \mathrm{l}^{13}$ reported that the near phoria shifts in the exophoric direction when subjects view a near target through $+2.00 \mathrm{D}$ additions. Therefore, near phoria can shift to the normal range in myopic subjects with near esophoria when they are wearing $+2.00 \mathrm{D}$ addition lenses for reading, whereas the near phoria may become more exophoric and even exceed the normal range in subjects with near orthophoria or exophoria. ${ }^{13}$ Consequently, near additions create an increased demand on positive fusional vergence, particularly in individuals with near exophoria. ${ }^{13} 14$ How myopic children with different phoria statuses address this mismatch of the accommodative and vergence systems has yet to be established. The present study investigates whether myopic children with different phoria statuses will change their near vision posture to attain a better oculomotor balance, while wearing the PALs.

\section{METHODS}

\section{Subjects}

The experiment was performed on 62 children (33 boys and 29 girls) aged $7-11$ years (mean \pm SD, 9.6 \pm 0.9 years). The children exhibited spherical equivalent refractive errors between -0.75 and $-4.75 \mathrm{D}$ (mean $\pm \mathrm{SD},-1.93 \pm 0.83 \mathrm{D}$ ) in both eyes, $<1.00 \mathrm{D}$ of astigmatism, and $<1.00 \mathrm{D}$ of anisometropia as measured using non-cycloplegic subjective refraction. The enrolled children were habitual single-vision spectacle wearers with no prior histories of wearing contact lenses, bifocal lenses or PALs and no history of strabismus, ocular pathology, trauma or surgery. All children had best-corrected Snellen visual acuities of at least 20/20 in both eyes for both distance and near. For the analysis, the subjects were divided into three phoria groups based on their near phoria, as measured using the modified Thorington technique at $33 \mathrm{~cm}: 18$ esophoric (>1 $\Delta$ eso), 18 orthophoric (between $1 \Delta$ eso and $1 \Delta$ exo) and 26 exophoric children $(>1 \Delta$ exo). The ages, genders, heights, refractive errors and near phorias of each group are described in table 1.

Informed consent was obtained from all subjects and their accompanying parents or guardians after the nature of the study and possible consequences 
Table 1 Mean $( \pm S D)$ ages, heights, refractive errors and near phorias of the enrolled myopic children

\begin{tabular}{|c|c|c|c|c|c|c|}
\hline & n & $\begin{array}{l}\text { Age } \\
\text { (years) }\end{array}$ & $\begin{array}{l}\text { Height } \\
(\mathrm{cm})\end{array}$ & $\begin{array}{l}\text { SE (OD) } \\
\text { (D) }\end{array}$ & $\begin{array}{l}\text { SE (OS) } \\
\text { (D) }\end{array}$ & $\begin{array}{l}\text { Near } \\
\text { phoria at } \\
33 \mathrm{~cm}(\Delta)\end{array}$ \\
\hline Eso & 18 & $9.3 \pm 1.2$ & $139.7 \pm 8.4$ & $-1.78 \pm 0.53$ & $-1.79 \pm 0.65$ & $4.3 \pm 1.9$ \\
\hline Ortho & 18 & $10.0 \pm 0.7$ & $145.1 \pm 5.4$ & $-2.17 \pm 0.90$ & $-2.22 \pm 0.95$ & $0.1 \pm 0.8$ \\
\hline Exo & 26 & $9.6 \pm 0.7$ & $143.6 \pm 7.5$ & $-1.90 \pm 0.86$ & $-1.79 \pm 0.90$ & $-4.2 \pm 1.7$ \\
\hline Total & 62 & $9.6 \pm 0.9$ & $142.9 \pm 7.4$ & $-1.94 \pm 0.79$ & $-1.92 \pm 0.86$ & $-0.5 \pm 3.9$ \\
\hline
\end{tabular}

were explained. The study was approved by the Ethics Committee of the School of Ophthalmology and Optometry, Wenzhou Medical University and followed the tenets of the Declaration of Helsinki.

\section{Procedures}

Each subject underwent a complete eye examination that included a case history, visual acuity, objective (Topcon KR 8800 autorefractor, Topcon Company, Japan) and subjective refraction, slit lamp examinations and a measurement of near phoria using the modified Thorington test at $33 \mathrm{~cm}$ with each child's best distance correction.

All subjects were provided with full-correction single vision lenses (SVLs) after the eye examinations. Posture measurements were collected after an adaptation of at least 2 weeks to the SVLs. During testing, the subjects were instructed to read grade-appropriate Chinese stories on standard A5-size paper that included 15 lines in Chinese Song font (14 pt). After reading, the subjects were asked three questions about the text passage that they read to confirm that they truly read and understood the text. Then, each subject was provided with PALs (Essilor Myopilux Pro, +2.00 D addition, progression length $=14.5 \mathrm{~mm}$, Essilor International S.A.). Similar posture measurements were acquired after an adaptation period to the PALs of at least 1 month.

\section{Posture measurement}

Our experiment was performed in a reading laboratory in which the lighting conditions were carefully controlled and maintained at $565 \mathrm{~lx}(560-570 \mathrm{~lx})$. The desk and chair heights (73 and $41 \mathrm{~cm}$, respectively) were the same as those used in local elementary schools and remained constant during the measurements.

Prior to the posture measurements, a photograph of the child was taken to measure the possible downward deviation of the frame using a previously described technique. ${ }^{16}$ This downward deviation was then accounted for in the subsequent calculations.

Reading distance, head tilt and ocular gaze angles were continuously recorded at $15 \mathrm{~Hz}$ with an electromagnetic motion tracking system (Fastrack, Polhemus, USA) that is commonly used for near posture measurements. ${ }^{17-19}$ Data related to the reading of one full page were used for the analyses. Reading distance was defined as the distance from the base of a child's nose to the centre of each line. Head tilt angle was defined as the angle in the sagittal plane between the head and the vertical upright position. Ocular gaze angle was defined as the angle in the sagittal plane between the normal line of the head and the child's line of sight and was corrected for the prismatic effects of the lenses. For both angles, positive values corresponded to downward head tilt or ocular gaze. The vertical prismatic effects were calculated based on the Prentice $\mathrm{law}^{20}$ for SVLs and based on the prismatic effects of the PALs along the meridian line, which were provided by the lens manufacturer. The addition powers of the PALs were calculated based on the power distribution along the meridian line as a function of the ocular gaze angle as provided by the lens manufacturer. Both vertical prismatic effects and addition values were adjusted for the downward deviation of the frame.

One-way analysis of variance was used to compare the means of the basic biometric characteristics (ie, age, height and refractive error) between the phoria groups and to compare the means of the postural data between the phoria groups within each lens type. A repeated measure analysis of variance was used to analyse the mean differences in the postural data. One-way analysis of variance was used to compare the means of the postural data between the phoria groups. Paired t tests were used to compare the postural data between the lens types within each phoria group. Statistical analyses were performed using IBM SPSS Statistics V.20.0, and $\mathrm{p}<0.05$ was considered statistically significant.

\section{RESULTS}

\section{Reading distance}

The mean reading distances of the 62 children were 30.8 $\pm 5.5 \mathrm{~cm}$ with the SVLs and $29.8 \pm 5.2 \mathrm{~cm}$ with the PALs. The lens type did not significantly influence the reading distance $(\mathrm{F}=1.81, \mathrm{p}=0.18)$. Using the SVLs, the mean reading distances of the 18 esophoric, 18 orthophoric and 26 exophoric children were $28.2 \pm 5.2 \mathrm{~cm}$ (SVL-eso), $32.1 \pm 5.5 \mathrm{~cm}$ (SVL-ortho) and $31.7 \pm 5.3 \mathrm{~cm}$ (SVL-exo), respectively (figure 1 ). With the PALs, the mean reading distances were $28.4 \pm 5.8 \mathrm{~cm}$ (PAL-eso), 30.9 $\pm 5.7 \mathrm{~cm}$ (SVL-ortho) and $30.1 \pm 4.3 \mathrm{~cm}$ (PAL-exo). The phoria status did not significantly influence the reading distances $(F=2.52, p=0.09)$. Similarly, the lens type did not influence the reading distance for each phoria group (eso, $\mathrm{t}=-0.17, \mathrm{p}=0.87$; ortho, $\mathrm{t}=1.09, \mathrm{p}=0.29$; exo, $\mathrm{t}=1.71, \mathrm{p}=0.10)$.

\section{Head tilt angle}

The mean head tilt angles were $31.3 \pm 9.5^{\circ}$ (SVLs) and 33.0 $\pm 8.7^{\circ}$ (PALs). The lens type did not significantly influence head

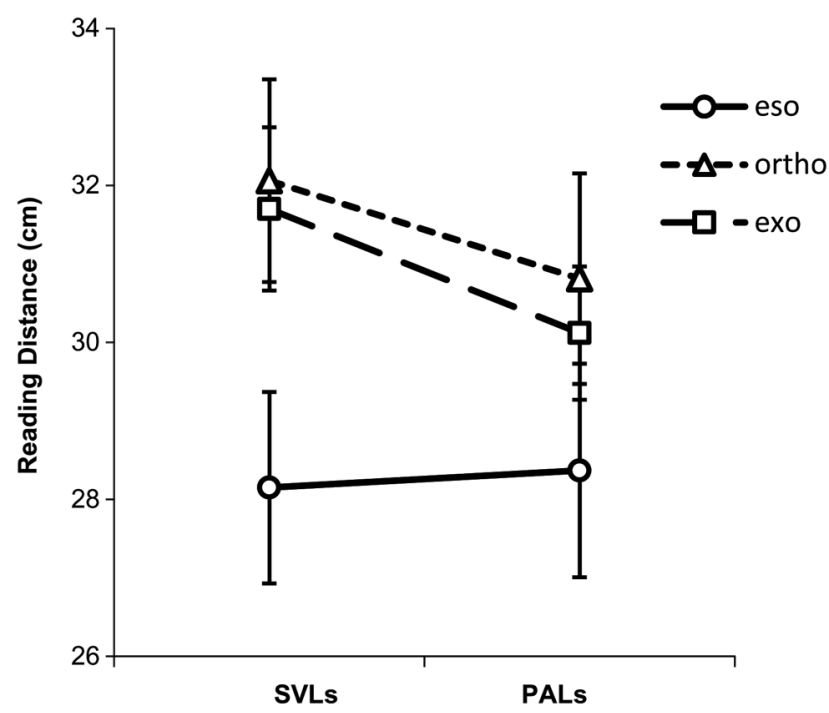

Figure 1 Reading distances according to lens type and near phoria status. The error bars represent the SE of the mean. PAL, progressive addition lens; SVL, single-vision lens. 
tilt angle $(\mathrm{F}=1.73, \mathrm{p}=0.19)$. Using the SVLs, the mean head tilt angles were $29.4 \pm 8.6^{\circ}$ (SVL-eso), $30.0 \pm 7.4^{\circ}$ (SVL-ortho) and $33.5 \pm 11.2^{\circ}$ (SVL-exo) (figure 2). Using the PALs, the mean head tilt angles were 28.6 $\pm 9.4^{\circ}$ (PAL-eso), 32.8 $\pm 6.8^{\circ}$ (PAL-ortho) and $36.3 \pm 8.3^{\circ}$ (PAL-exo). Combining both lens types, the phoria status significantly influenced head tilt angle $(\mathrm{F}=3.36, \mathrm{p}=0.04)$, and head tilt angle was significantly increased in children with exophoria compared with those who had esophoria $(p=0.04)$. Phoria status significantly influenced head tilt angle with the PALs $(F=4.68, p=0.01)$ but not with the SVLs $(\mathrm{F}=1.21, \mathrm{p}=0.31)$. With the PALs, the head tilt angle was significantly increased in children with near exophoria compared with those who had near esophoria $(p=0.003)$, and no significant differences were observed for the other phoria groups $(p>0.05)$. The lens type did not significantly influence head tilt angle for each phoria group (eso, $t=-0.38, p=0.71$; ortho, $\mathrm{t}=1.42, \mathrm{p}=0.17$; exo, $\mathrm{t}=1.45, \mathrm{p}=0.16$ ).

\section{Ocular gaze angle}

The mean ocular gaze angles were $20.7 \pm 7.2^{\circ}$ (SVLs) and 17.5 $\pm 7.2^{\circ}$ (PALs). The ocular gaze angle decreased significantly with the PALs $(\mathrm{F}=9.25, \mathrm{p}=0.004)$. Using the SVLs, the mean ocular gaze angles were $22.3 \pm 6.5^{\circ}$ (SVL-eso), $20.6 \pm 4.9^{\circ}$ (SVL-ortho) and $19.6 \pm 8.9^{\circ}$ (SVL-exo) (figure 3). For the PALs, the mean ocular gaze angles were $20.4 \pm 6.8^{\circ}$ (PAL-eso), $19.0 \pm 6.2^{\circ}$ (PAL-ortho) and $14.3 \pm 7.0^{\circ}$ (PAL-exo) (figure 3). Combining both lens types, the phoria status significantly influenced the ocular gaze angle $(F=3.22, p=0.047)$. Phoria status significantly influenced the ocular gaze angle with the PALs $(\mathrm{F}=5.17$, $\mathrm{p}=0.009)$ but not with SVLs $(\mathrm{F}=0.76, \mathrm{p}=0.47)$. With the PALs, the ocular gaze angle was significantly reduced in children with the near exophoria compared with those who had near esophoria $(p=0.004)$ and orthophoria $(p=0.025)$. The ocular gaze angle significantly decreased in exophoric children using PALs compared with SVLs $(\mathrm{t}=-3.18, \mathrm{p}=0.04)$, but a corresponding significant difference was not observed in esophoric $(\mathrm{t}=-1.20$, $\mathrm{p}=0.25)$ or orthophoric children $(\mathrm{t}=-1.04, \mathrm{p}=0.32)$.

\section{Addition power}

When myopic children read using their PALs, the mean addition powers they actually used were $1.19 \pm 0.55 \mathrm{D}$ (PAL-eso), 1.14

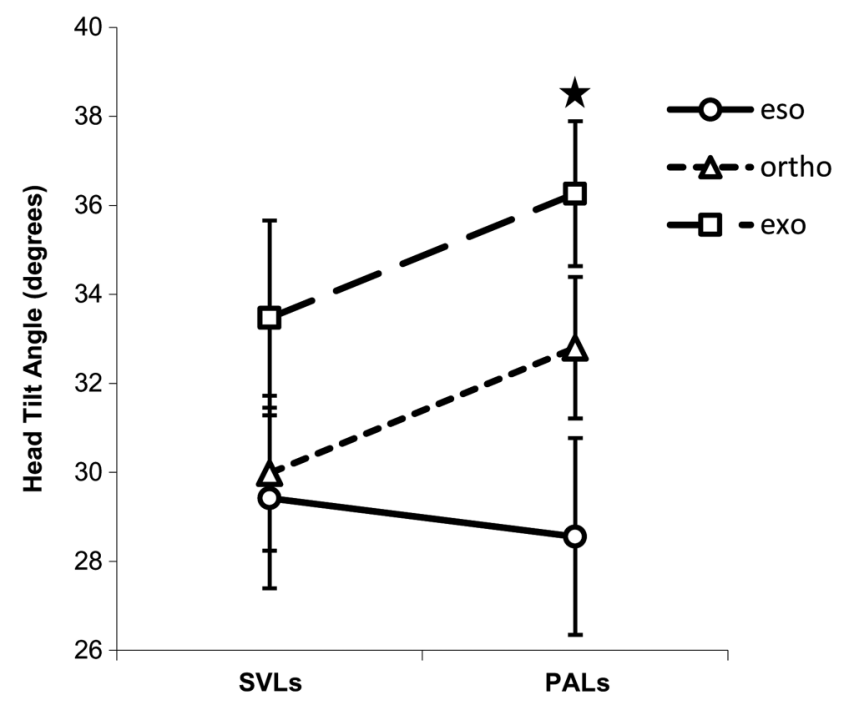

Figure 2 Head tilt angle according to lens type and near phoria status. The error bars represent the SE of the mean ( $\star$ significant difference between esophoric and exophoric children in PALs, $\mathrm{p}=0.003$ ). $P A L$, progressive addition lens; $S V L$, single-vision lens.

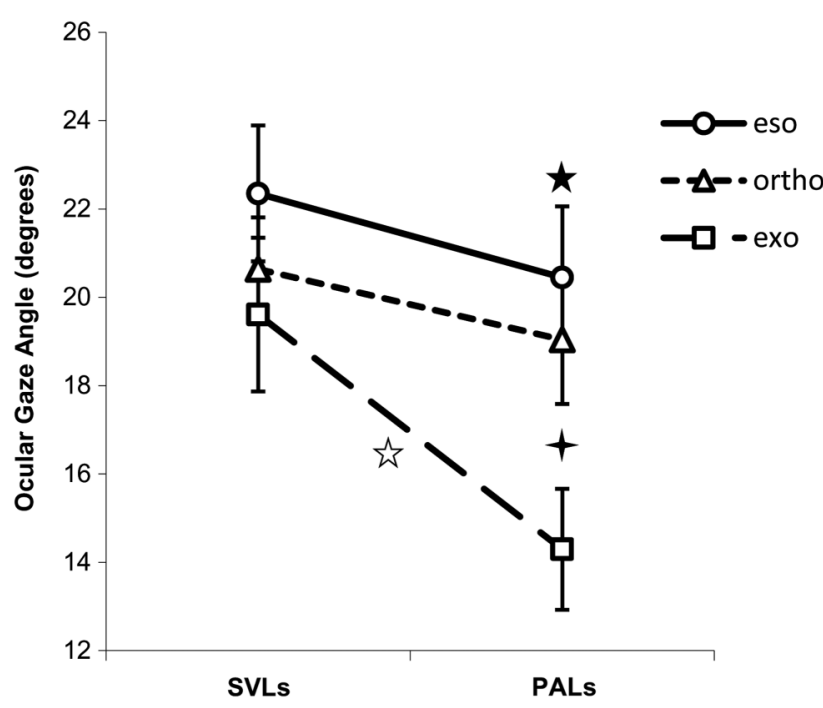

Figure 3 Ocular gaze angle according to lens type and near phoria status. The error bars represent the SE of the mean ( $\star$ significant difference between esophoric and exophoric children in PALs, $p=0.004$; + significant difference between exophoric and orthophoric children in PALs, $p=0.025 ; i$ significant difference between PALs and SVLs in exophoric children, $\mathrm{p}=0.04)$. $P A L$, progressive addition lens; $S V L$, single-vision lens.

$\pm 0.55 \mathrm{D}$ (PAL-ortho) and $0.84 \pm 0.55 \mathrm{D}$ (PAL-exo) as calculated based on the ocular gaze angle and the downward deviation of the frame. The mean addition power employed by esophoric children was significantly greater than exophoric children $(\mathrm{p}=0.04)$.

\section{DISCUSSION}

In our study, when all the children were considered, only ocular gaze angle during reading was affected by the use of PALs compared with SVLs. When the children were grouped according to their phoria status, near esophoric or orthophoric children using the PALs exhibited head and eye postures that were similar to those exhibited during the use of SVLs. In contrast, exophoric children exhibited decreased ocular gaze angles with the PALs. Furthermore, exophoric children exhibited increased head tilt angles and decreased ocular gaze angles compared with esophoric children, resulting in viewing through a lower near addition power. These results may partially explain the treatment differences between phoria groups that have been observed in myopia control trials using PALs. ${ }^{3-5} 15$

A previous study reported that reading conditions, such as a relaxed armchair setting or a chair/desk setting, and the size of the child relative to the desk height can strongly influence reading distance. ${ }^{21}$ Moreover, the comfort and familiarity of a reading posture appear to be important determinants of reading distance and posture. ${ }^{21}$ In our study, myopic children adopted similar reading distances (SVLs, $30.8 \mathrm{~cm}$; PALs, $29.8 \mathrm{~cm}$ ) and head tilt angles (SVLs, $31.3^{\circ}$; PALs, $33.0^{\circ}$ ) independent of their lens type or phoria status. We simulated a typical school desk/ chair setting and used grade-appropriate stories such that these common and familiar conditions made the children feel comfortable and allowed them to maintain their habitual head postures.

With the SVLs, the phoria status did not significantly influence eye or head posture. With the PALs, near exophoric children exhibited a $6.2^{\circ}$ reduction in ocular gaze angle and a $7.7^{\circ}$ 
increase in head tilt angle compared with those who had esophoria, as well as a $4.7^{\circ}$ reduction in ocular gaze angle and a $3.5^{\circ}$ increase in head tilt angle compared with those who had orthophoria. In other words, exophoric children used an upper portion of the PALs compared with esophoric or orthophoric children. Based on the design of the PALs used in this study, we calculated the near addition power of the PALs that corresponded to the average ocular gaze angle used for reading while accounting for the downward deviation of the frame. On average, exophoric children experienced 0.36 and $0.30 \mathrm{D}$ less addition powers than esophoric and orthophoric children, respectively, while reading. Based on the accommodative lag theory, near additions reduce accommodative lag during near work, thereby decreasing hyperopic retinal blur, axial elongation and myopia progression. ${ }^{22}$ During near work, in esophoric myopic children, higher near additions reduce accommodative error and also the demand on negative fusional vergence, thus enhancing oculomotor balance. ${ }^{13}$ Higher near addition values used by esophoric myopic children may be a factor to explain the different effects in reducing myopia progression between phoria groups in PALs studies. ${ }^{3-5} 15$ In myopic children with exophoria, the addition may lead to a conflict between the reduced accommodative demand and the relatively large vergence demand, ${ }^{13}{ }^{23}$ resulting in eye strain. ${ }^{24}$ Cheng and colleagues $^{14}$ reported that the average near exophoria increased to 6 $\Delta$ in myopic children wearing $+2.00 \mathrm{D}$ addition lenses, which is beyond the normal range. Therefore, compared with esophoric or orthophoric children, exophoric children could use less addition power to exert less vergence effort and thus reduce potential eye strain.

Although, we carefully instructed and reminded the children and their parents on how to use the PALs when we dispensed these lenses, we still found that several children did not use the near addition for reading and had the spectacles placed low on their faces. Consequently, even in myopic children with esophoria, the mean addition power they used was just $1.19 \mathrm{D}$. This result indicates that only $60 \%$ of the full addition power $(+2.00 \mathrm{D})$ was used. Hasebe $e t a l^{16}$ proposed that downward deviations of PALs (ie, the distances from the subject's corneal light reflection point to the PALs fitting cross) could lead to insufficient addition values by limiting the access to the lower portion of the lens as children perform near vision work. Although the frames were properly adjusted when initially given to the children, we found that $27 \%$ of the children (17 out of 62) (eso, 4; ortho, 6; exo, 7) had downward deviations of $>2 \mathrm{~mm}$ after the adaptation period of at least 1 month. Consequently, the children had to lower their eyes further, if they wanted to access the full near vision power of their lenses, which may reduce the overall therapeutic effect of the PALs. Therefore, frequent frame adjustments are recommended in myopia control trials with PALs. In addition, the possibility for exophoric children to wear PALs deliberately lower to avoid looking through the addition cannot be excluded.

Contributors JB set up the testing room, helped conceive the study, performed the statistical analyses and drafted and revised the manuscript. YW helped set up the testing room and conducted the study. ZZ and XY performed most of the subject recruitment, processed most of the subjects and analysed numerous subject images. RT analysed some of the subject images and performed some of the statistical analysis. BD helped conceive the study and supervised some of the work. HC supervised the project and was involved in discussions and decisions at each step of the project. He reviewed and approved all aspects of data analysis and manuscript drafting.

Funding This study was supported by the International S\&T Cooperation Program of China (grant no. 2014DFA30940) and the National Health and Family Planning
Commission of the People's Republic of China (grant no 201302015). Partial funding was provided by Essilor International S.A.

Competing interests None declared.

\section{Patient consent Obtained.}

Ethics approval The Ethics Committee of the School of Ophthalmology and Optometry, Wenzhou Medical University.

Provenance and peer review Not commissioned; externally peer reviewed.

Open Access This is an Open Access article distributed in accordance with the Creative Commons Attribution Non Commercial (CC BY-NC 4.0) license, which permits others to distribute, remix, adapt, build upon this work non-commercially, and license their derivative works on different terms, provided the original work is properly cited and the use is non-commercial. See: http://creativecommons.org/ licenses/by-nc/4.0/

\section{REFERENCES}

1 Berntsen DA, Sinnott LT, Mutti DO, et al. A randomized trial using progressive addition lenses to evaluate theories of myopia progression in children with a high lag of accommodation. Invest Ophthalmol Vis Sci 2012;53:640-9.

2 Correction of Myopia Evaluation Trial 2 Study Group for the Pediatric Eye Disease Investigator G. Progressive-addition lenses versus single-vision lenses for slowing progression of myopia in children with high accommodative lag and near esophoria. Invest Ophthalmol Vis Sci 2011;52:2749-57.

3 Yang Z, Lan W, Ge J, et al. The effectiveness of progressive addition lenses on the progression of myopia in Chinese children. Ophthalmic Physiol Opt 2009;29:41-8.

4 Hasebe $\mathrm{S}$, Ohtsuki $H$, Nonaka $T$, et al. Effect of progressive addition lenses on myopia progression in Japanese children: a prospective, randomized, double-masked, crossover trial. Invest Ophthalmol Vis Sci 2008;49:2781-9.

5 Gwiazda J, Hyman L, Norton T, et al. Accommodation and related risk factors associated with myopia progression and their interaction with treatment in COMET children. Invest Ophthalmol Vis Sci 2004;45:2143-51.

6 Leung JT, Brown B. Progression of myopia in Hong Kong Chinese schoolchildren is slowed by wearing progressive lenses. Optom Vis Sci 1999;76:346-54.

7 Edwards M, Li R, Lam C, et al. The Hong Kong progressive lens myopia control study: study design and main findings. Investig Ophthalmol Vis Sci 2002;43:2852-8.

8 Gwiazda J, Thorn F, Bauer J, et al. Myopic children show insufficient accommodative response to blur. Invest Ophthalmol Vis Sci 1993;34:690-4.

9 Charman WN. Near vision, lags of accommodation and myopia. Ophthalmic Physiol Opt 1999;19:126-33.

10 Wallman J, Winawer J. Homeostasis of eye growth and the question of myopia. Neuron 2004;43:447-68.

11 Goss DA. Childhood myopia. In: Grosvenor T, Flom M, eds. Refractive anomalies: research and clinical applications. Boston: Butterworth-Heinemann, 1991:81-103.

12 Rosenfield M, Carrel MF. Effect of near-vision addition lenses on the accuracy of the accommodative response. Optometry 2001;72:19-24.

13 Jiang $B$, Tea $Y, O^{\prime}$ Donnell $D$. Changes in accommodative and vergence responses when viewing through near addition lenses. Optometry 2007:78:129-34.

14 Cheng D, Schmid KL, Woo GC. The effect of positive-lens addition and base-in prism on accommodation accuracy and near horizontal phoria in Chinese myopic children. Ophthalmic Physiol Opt 2008;28:225-37.

15 Gwiazda J, Hyman L, Hussein $M$, et al. A randomized clinical trial of progressive addition lenses versus single vision lenses on the progression of myopia in children. Invest Ophthalmol Vis Sci 2003;44:1492-500.

16 Hasebe S, Nakatsuka C, Hamasaki I, et al. Downward deviation of progressive addition lenses in a myopia control trial. Ophthalmic Physiol Opt 2005;25:310-4.

17 Haro C, Poulain I, Drobe B. (OR-132) Investigation of working distance in myopic and nonmyopic children [abstract]. Optom Vis Sci 2000;77(Suppl):189.

18 Drobe B, Seow E, Tang F. Clinical evaluation of working distance in Caucasian and Chinese adults: a comparison study in France and Singapore [abstract]. Invest Ophthalmol Vis Sci 2007;48:962.

19 Drobe B, Seow E, Bao J, et al. Near vision posture in myopic Chinese children [abstract]. Invest Ophthalmol Vis Sci 2011;52:2701.

20 Jalie M. The principles of ophthalmic lenses. 4th edn. London: Association of Dispensing Opticians, 1984:67-88.

21 Wang Y, Bao J, Ou L, et al. Reading behavior of emmetropic schoolchildren in China. Vision Res 2013;86:43-51.

22 Goss DA, Rainey BB. Relationship of accommodative response and nearpoint phoria in a sample of myopic children. Optom Vis Sci 1999;76:292-4.

23 Goss DA. Effect of bifocal lenses on the rate of childhood myopia progression. Am J Optom Physiol Opt 1986;63:135-41.

24 Brown B, Edwards MH, Leung JTM. Is esophoria a factor in slowing of myopia by progressive lenses? Optom Vis Sci 2002;79:638-42. 